\title{
URETERES ECTÓPICOS EM CÃES
}

\author{
Tales Dias do Prado ${ }^{1}$, Talliana Cabral Gouveia ${ }^{2}$, Anaíza Simão Zucatto do Amaral ${ }^{3}$, \\ Rejane Guerra Ribeiro ${ }^{4}$ \\ ${ }^{1}$ Universidade Estadual Paulista, Faculdade de Ciências Agrárias e Veterinárias, \\ Jaboticabal, SP \\ 2 Universidade de Rio Verde, Rio Verde - GO \\ 3 Universidade de Rio Verde, Rio Verde - GO \\ 4 Universidade Estadual Paulista, Faculdade de Ciências Agrárias e Veterinárias, \\ Jaboticabal, SP \\ Autor correspondente: talesprado@yahoo.com.br
}

Recebido em: 05/12/2014 - Aprovado em: 14/12/2014 - Publicado em: 15/12/2014

\section{RESUMO}

Ureteres ectópicos em cães constituem achados raros, congênitos e também de extrema importância na clínica de pequenos animais. São anomalias adquiridas durante a gestação, onde um ou ambos os ureteres desembocam exterior ou interiormente à vesícula urinária, ligando-se geralmente à uretra, sendo classificados em intramurais ou extramurais conforme o curso do ureter até seu orifício terminal. Os sinais clínicos dos portadores dessa anomalia são variáveis, sendo mais comum a incontinência urinária. O diagnóstico é realizado através das manifestações clínicas, exame físico completo, urografia excretora e ultrassonografia do paciente. $O$ tratamento para esta anomalia é somente cirúrgico, no qual é realizada a correção do ligamento dos ureteres. A principal complicação pós-operatória é a incontinência urinária persistente. O objetivo deste trabalho é fazer uma revisão bibliográfica sobre ureteres ectópicos, ressaltando a definição, fisiopatogenia, principais sinais clínicos, diagnóstico e correção cirúrgica.

PALAVRAS- CHAVE: Anomalia congênita, incontinência urinária, ectopia ureteral.

\section{ECTOPIC URETERS IN DOGS}

\begin{abstract}
Ectopic ureters in dogs are rare congenital findings, extremely important for the small animal clinics and surgery. These anomalies are acquired during pregnancy, when one or both ureters empty into outside or inside the urinary bladder, connecting usually to the urethra. They may be classified as intramural and extramural, depending on the course of the ureter to the terminal hole. Clinical signs of patients with this abnormality are variable and the most common is urinary incontinence. The diagnosis is made through clinical manifestations, physical examination, excretory urography and ultrasonography. The treatment is exclusively the surgical correction in which the ureter ligament correction is performed. The main postoperative complication is persistent urinary incontinence. The aim of this work is to make a review of ectopic ureters, emphasizing the definition, pathogenesis, main clinical signs, diagnosis and surgical correction.
\end{abstract}

KEYWORDS: Congenital anomaly, urinary incontinence, ureteral ectopia. 


\section{INTRODUÇÃO}

Ureteres ectópicos iniciam-se no período gestacional, onde um ou ambos os ureteres se direciona para regiões fora do trígono vesical. Esta anomalia é resultante da falha na diferenciação dos ductos mesonéfricos, que leva ao mau posicionamento do botão ureteral (COSTA NETO et al., 2011). Nas fêmeas, os ureteres ectópicos podem desembocar no colo da vesícula urinária, na uretra, útero, ou até mesmo na vagina. Enquanto que nos machos, terminam no colo da vesícula urinária e na uretra prostática (GRANT \& FORRESTER, 2008).

BIANCHI et al., (2013) classificam os ureteres ectópicos como intramurais ou extramurais, sendo que são observados, mais comumente, os intramurais. Ureteres ectópicos intramurais se aderem à mucosa da vesícula urinária. Os extramurais passam exteriormente à vesícula urinária (BIANCHI et al., 2013). Podem ser, ainda, uni ou bilaterais (COSTA NETO et al., 2011).

As raças Labrador Retriever, Golden Retriever, Husky Siberiano, West Highland White Terrier e Poodles são as que apresentam maior predisposição. $O$ principal sinal clínico é a incontinência urinária. Outros sinais podem ser observados como dermatite perivulvar ou prepucial, coloração amarelada da pelagem devido à incontinência urinária (BIANCHI et al., 2013). Infecção urinária bacteriana é frequentemente visualizada devido à ausência de peristaltismo ureteral (COSTA NETO et al., 2011).

O diagnóstico é realizado mediante ao exame de urografia excretora, cistoscopia ou ultrassonografia. Porém a urografia excretora é o exame de eleição para o diagnóstico definitivo de ectopia ureteral (BIANCHI et al., 2013). O tratamento é exclusivamente cirúrgico, onde é realizado o reimplante do ureter ectópico na região do trígono vesical. Se for extramural (ureteroneocistostomia), intramural (neoureterostomia) (BIANCHI et al., 2013).

\section{ANATOMIA E FISIOLOGIA DO SISTEMA URINÁRIO INFERIOR E SUPERIOR DOS CÃES}

O sistema urinário dos pequenos animais é constituído por: dois rins bilaterais, sendo o direito ligeiramente mais cranial que o esquerdo, dois ureteres que se ligam na vesícula urinária e a uretra sendo o último canal do sistema (MCLOUGHLIN \& BJORLING, 2007).

\section{Rins}

Os rins possuem formato de "feijões", localizam-se na cavidade abdominal, retroperitonealmente, próximo à junção toracolombar, ao lado da aorta e veia cava caudal. Eles são deslocados durante a respiração através dos movimentos do diafragma. $\mathrm{O}$ rim direito está firmemente aderido por estar comumente relacionado ao fígado, e o rim esquerdo pode ser caudalmente deslocado pelo estômago cheio, pois não está firmemente aderido. Porém, ambos são igualmente móveis. Sendo assim, o rim direito está brevemente mais cranial que o esquerdo (MCLOUGHLIN \& BJORLING, 2007).

Segundo BRAGATO (2013), os rins recebem cerca de $25 \%$ do débito cardíaco e têm como principal função filtrar o sangue e excretar através da urina os resíduos metabólicos como hormônios e componentes exógenos. Algumas substâncias requisitadas pelo organismo, como as proteínas de baixo peso molecular, os 
eletrólitos e a água são reaproveitados pelos rins no mecanismo de reabsorção. Os rins são responsáveis pelo controle da pressão arterial sistêmica, através dos mecanismos de renina, angiotensina e aldosterona. Também, participam do mecanismo da eritropoiese (MCLOUGHLIN \& BJORLING, 2007).

\section{Ureteres}

Os ureteres são orifícios ligados aos rins especificamente na pelve renal, que conduzem a urina até a vesícula urinária, fixando-se na região chamada trígono vesical. Circundam a vesícula urinária através de uma bainha de tecido conjuntivo, onde se inserem fascículos do músculo detrusor (MCLOUGHLIN \& BJORLING, 2007). Segundo MCLOUGHLIN \& BJORLING (2007), durante a micção, o lúmen do ureter pode dilatar-se 17 vezes, devido ao seu achatamento do lúmen e 0 adelgaçamento do revestimento muscular.

\section{Vesícula urinária}

A vesícula urinária é um reservatório de urina, variando no tamanho, posição e forma, resultante da quantidade de urina contida no órgão. É um órgão oco e na parede possui fibras musculares lisas interdigitantes, mais conhecidas como músculo detrusor. Possui o colo (junção vesicouretral), corpo que se encontra na superfície dorsal (teto) e ventral (assoalho), e um vértice (ápice). Quando está distendida encontra-se no assoalho do abdome na cavidade abdominal e quando vazia encontra-se na pelve dificultando o acesso cirúrgico (MCLOUGHLIN \& BJORLING, 2007). Segundo GRAUER (2010), uma prolongada distensão da vesícula urinária pode lesionar o neurônio motor inferior, resultando em incontinência urinária, o sinal mais comum desta lesão é a facilidade de esvaziá-la por compressão.

\section{Uretra}

A uretra possui funções diferentes de acordo com o sexo do animal. Nas fêmeas, sua função é somente via excretora, onde é eliminada a urina do organismo. Nos machos, possui duas funções: via excretora da urina e do sêmen. Portanto, a uretra do macho se torna mais longa que a da fêmea (MCLOUGHLIN \& BJORLING, 2007).

Segundo MCLOUGHLIN \& BJORLING (2007), a uretra das fêmeas é relativamente curta e se distende mais que a dos machos. $A$ uretra dos machos é dividida em partes prostática, pélvica (membranosa) e cavernosa (peniana). Portanto é mais comum infecção urinária em fêmeas.

\section{URETERES ECTÓPICOS}

Ureteres ectópicos se constituem em uma anomalia congênita, ou seja, adquirida durante a gestação, onde um ou ambos os ureteres não terminam anatomicamente na região do trígono vesical. Nas fêmeas, os ureteres ectópicos podem terminar no colo da vesícula urinária, na uretra ou no útero, ou até mesmo na vagina. Enquanto que nos machos, terminam no colo da bexiga e na uretra prostática (GRANT \& FORRESTER, 2008). 
Esta anomalia é resultante da disembriogênese do botão ureteral, devido ao mau-posicionamento do botão ao longo do ducto mesonéfrico. Quanto mais lateralmente desviada for a posição do botão ureteral mediante o ducto mesonéfrico, mais anormal será a posição final do segmento do ureter e do orifício ureteral. Isso pode justificar os diferentes aspectos morfológicos dos ureteres ectópicos (MCLOUGHLIN \& BJORLING, 2007).

Segundo MCLOUGHLIN \& BJORLING (2007), esta anomalia é classificada em extramurais e intramurais. Em animais de pequeno porte, ureteres ectópicos extramurais ocorrem com menos frequência. Os ureteres ectópicos extramurais contornam a vesícula urinária sem conectar-se anatomicamente, abrindo-se diretamente no colo da vesícula urinária, na uretra, na vagina ou até mesmo no útero (COSTA NETO et al., 2011).

Os ureteres ectópicos intramurais escavam-se por baixo da camada submucosa e se anexa na superfície dorsal ou dorsolateral da vesícula urinária, mas não desembocam no trígono, e, sim, no colo da vesícula urinária, uretra ou vagina (COSTA NETO et al., 2011). Existem diversas variações anatômicas dos ureteres intramurais, como calhas ureterais, duas aberturas ureterais em somente um ou em ambos os ureteres, várias fenestras ao longo do túnel da camada submucosa e dois túneis na camada submucosa que se abrem especificamente por um orifício (MCLOUGHLIN \& BJORLING, 2007).

Segundo COSTA NETO et al., (2011), os ureteres ectópicos podem ainda ser classificados como uni ou bilaterais. Além de ser uma anomalia congênita, há também uma predisposição racial, que varia de um continente para outro. Há relatos que as raças mais predispostas nos Estados Unidos são Husky Siberiano, Newfoundland, Bulldog, West Highland White Terrier, Fox Terrier de pelo de arame Terra-Nova e Poodle. No Reino Unido, as raças mais frequentemente acometidas são Golden Retriever, Labrador, to Edge him Collie, Skye Terrier, Bulldog, Briard e Griffin. No Brasil, não há relato das raças mais predispostas.

A ectopia ureteral além de ser observada em cães, já foi identificada também em gatos, ratos, equinos, bovinos, camelídeos, aves e seres humanos. Além disso, os relatos encontrados são mais frequentes em fêmeas do que em machos. Isso pode ser devido à óbvia incontinência urinária notada em fêmeas. E, em machos, a anomalia pode ser subdetectada, pois incontinência urinária em cães com ureteres ectópicos pode não ser clinicamente visualizada, devido à extensão relativa do esfíncter externo, que pode colocar-se distalmente à passagem da urina, resultando no enchimento retrógrado da vesícula urinária (MCLOUGHLIN \& BJORLING, 2007).

A ocorrência de ectopia ureteral tem sido relatada e diagnosticada juntamente com outras anormalidades do trato urinário, incluindo rins irregulares, de tamanhos pequenos ou até mesmo ausentes, hidronefrose, ureter dilatado, ureter tortuoso, bexiga pélvica, persistência de úraco e junção ureterovesical anormal (SILVA et al., 2012).

\section{SINAIS CLÍNICOS}

O mais clássico e evidente sinal clínico desta anomalia é a incontinência urinária intermitente ou contínua desde o nascimento do animal. Porém, pode manter a capacidade normal de micção (GRANT \& FORRESTER, 2008). Também, pode ser observada dermatite perivulvar ou prepucial devido à assadura urinária, hematúria, piúria e cistites recorrentes (MCLOUGHLIN \& BJORLING, 2007). 
Segundo MCLOUGHLIN \& BJORLING (2007), a incontinência urinária ocorre devido ao refluxo de urina distal ao trígono e, posteriormente, esfíncter urinário interno, ou da ruptura física do músculo do esfíncter através de um ureter intramural deslocado ou até mesmo por incompetência do esfíncter primário.

Hemograma e perfil bioquímico geralmente encontram-se com resultados dentro da normalidade, a não ser que existem anormalidades relacionadas ao trato urinário superior que diminuam a função renal. ITU foi observada em $64 \%$ dos pacientes com esta anomalia (MCLOUGHLIN \& BJORLING, 2007).

\section{DIAGNÓSTICO}

O diagnóstico de ectopia ureteral é realizado mediante à (anamnese), onde a principal queixa do proprietário geralmente é a incontinência urinária, associado ao exame físico completo (GRANT \& FORRESTER, 2008). Também devem ser realizados exames laboratoriais incluindo função renal, exame de urina e exames complementares que são fundamentais incluindo radiografia contrastada (como urografia excretora endovenosa) com frequência, cistografia de contraste positivo, cistografia de duplo contraste, uretrografia retrógrada, vaginoscopia e citoscopia, fluoroscopia, tomografia computadorizada por contraste e ultrassonografia abdominal (MCLOUGHLIN \& BJORLING, 2007).

A urografia excretora é o principal exame para concluir o diagnóstico, pois estabelece informações através da imagem, se a ectopia ureteral é uni ou bilateral, sobre o tamanho, localização, morfologia e locais de implantações dos ureteres (OLIVEIRA et al., 2013). Ureteres dilatados são os achados radiográficos anormais mais frequentemente relatados em cães com ectopia ureteral. Em cães, os ureteres são considerados dilatados quando o diâmetro foi maior que $3,0 \mathrm{~mm}$. A dilatação ocorre devido à obstrução parcial ou intermitente do fluxo urinário. Esta dilatação ureteral está relacionada, principalmente, com ureteres intramurais, pois geralmente estão deslocados para a uretra distal ou para a vagina (MCLOUGHLIN \& BJORLING, 2007).

Segundo MCLOUGHLIN \& BJORLING (2007), a análise direta do TUI através de um cistoscópio rígido ou flexível, por abordagem transuretal, facilitou bastante 0 diagnóstico e classificação dos ureteres ectópicos e das anormalidades associadas ao TUI. A uretrocistoscopia transuretal disponibiliza bastante informação sobre a localização e a morfologia de cada ureter no segmento terminal. A falta de visualização de um ou ambos condutos ureterais para a vesícula urinária é sugestiva (porém não é diagnóstico definitivo) de ectopia ureteral. Portanto, deve ser realizado o exame completo de toda a uretra, vestíbulo e abóbada vaginal cranial, e identificar especificamente o deslocamento do orifício ureteral, para que seja diagnosticada definitivamente ectopia ureteral.

\section{Diagnósticos diferenciais}

Deve-se incluir como diagnóstico diferencial outras anomalias funcionais ou estruturais do trato urinário inferior, como os urólitos, infecções urinárias, incompetência do esfíncter ureteral, disfunção renal/hepática, anormalidades endócrinas, distúrbios neurogênicos e neoplasias (SILVA et al., 2012). Também, deve-se incluir hipoplasia vesical, uma anomalia rara, que quando ocorre está exclusivamente relacionada com ureteres ectópicos bilaterais (CHEW et al., 2011). 


\section{TRATAMENTO}

Segundo GRANT \& FORRESTER (2008), o tratamento de escolha e primordial é a correção cirúrgica. A cirurgia obtém sucesso em aproximadamente $50 \%$ dos pacientes com ureteres ectópicos; os demais $50 \%$ dos pacientes continuam apresentando incontinência urinária. Somente um terço desses animais respondem ao tratamento medicamentoso. É essencial a inspeção de todo o sistema urinário antes do reparo do ureter. Caso o rim apresente hidronefrose ou pielonefrite extrema, o mesmo deve ser removido juntamente com o ureter (COSTA NETO et al., 2011; FOSSUM, 2008).

\section{Ureteroneocistostomia}

Ureteroneocistostomia é a nomenclatura científica utilizada para a técnica cirúrgica de ureteres ectópicos extramural, ou seja, quando os ureteres localizam-se posteriormente à vesícula urinária (FOSSUM, 2008). O principal objetivo é normalizar o fluxo de urina do ureter para a vesícula urinária, sendo assim, a incontinência urinária tende a normalizar-se quando relacionada à ectopia ureteral (GRANT \& FORRESTER, 2008).

O proprietário deve estar ciente que a incontinência urinária associada com a ectopia ureteral pode ou não ser corrigida com a ureteroneocistostomia. Incontinência urinária que persiste mesmo após a intervenção cirúrgica pode estar relacionado com a anormalidade de desenvolvimento do esfíncter uretral ou até mesmo da presença de segmento remanescente da parte distal do ureter no esfíncter (GRANT \& FORRESTER, 2008). Deve-se avaliar todo o exame hematológico do animal principalmente o perfil bioquímico. Em caso de alterações, as mesmas devem ser corrigidas, previamente, a cirurgia para que se obtenham melhores resultados tanto no trans como no pós-operatório. É importante também avaliar as arritmias cardíacas através do eletrocardiograma (ECG). Se possível realizar uma urocultura para iniciar com um antibiótico eficaz na tentativa de diminuir ou erradicar a ITU (FOSSUM, 2008).

Segundo FOSSUM (2008), é necessário ter cautela no protocolo anestésico, principalmente, se a função renal e hepática estiverem comprometidas. Realizar anestesia epidural, para reduzir ao máximo a dor do animal. Posicioná-lo em decúbito dorsal e fazer toda técnica de antissepsia tanto a prévia como a definitiva. Deve-se fazer laparotomia retro umbilical na linha média ventral estendendo a incisão até o púbis para avaliar TUI. Uma sutura de suporte é feita no ápice da vesícula urinária, para facilitar a manipulação durante a cirurgia. Mediante esta sutura de suporte, obtém-se a exposição de grande parte da porção intrapélvica da uretra das fêmeas no interior da cavidade abdominal (MCLOUGHLIN \& BJORLING, 2007).

Posteriormente, deve-se localizar o ureter ectópico, fazer a dissecação e, em seguida, o reimplante dentro do lúmen da vesícula urinária, através de um túnel intramural ou usando um simples restabelecimento transverso. A primeira técnica pode ter retorno mais rápido da função ureteral (FOSSUM, 2008). Liga-se o ureter e secciona-se o local que será fixado na superfície serosa da uretra, da vagina ou do útero e coloca-se uma sutura de apoio na extremidade proximal do ureter seccionado (MCLOUGHLIN \& BJORLING, 2007). Posteriormente, é necessário fazer uma incisão na mucosa da vesícula urinária e criar um pequeno túnel oblíquo na parede da vesícula, especificamente na submucosa. Após fazer uma incisão oblíqua 
na extremidade do ureter, o mesmo deve ser suturado com fio absorvível dentro da mucosa da vesícula urinária (FOSSUM, 2008).

\section{Neoureterostomia}

Esta é a nomenclatura científica utilizada para a técnica cirúrgica de ureteres ectópicos intramurais, ou seja, quando se localizam no interior da vesícula urinária precisamente aderida à submucosa vesical (FOSSUM, 2008). Realiza-se incisão no interior da vesícula urinária próxima à uretra. Colocam-se suturas de reparo para auxiliar na retração da borda da parede da vesícula urinária. É necessário, então, avaliar o trígono para aberturas ureterais. Em seguida, deve-se ocluir digitalmente a uretra, dilatando-a, a fim de identificar um inchaço da submucosa ou aresta dentro da parede da vesícula urinária (FOSSUM, 2008).

Com o escalpe, faz-se uma incisão longitudinal de três a cinco $\mathrm{mm}$ através da mucosa da vesícula urinária para dentro do lúmen ureteral. É importante suturar a mucosa ureteral à vesícula urinária com fio absorvível e sutura simples interrompida. Fixa-se um cateter de 3,5 ou $5 \mathrm{Fr}$ distalmente no interior do ureter, próximo à porção distal do novo estoma e introduzir uma ou duas suturas não-absorvíveis a partir da superfície serosa ao redor do tubo, permanecendo abaixo da mucosa (FOSSUM, 2008).

\section{CONSIDERAÇÕES FINAIS}

Ureteres ectópicos constituem um defeito congênito de extrema importância terapêutica, mas que ainda não é uma anomalia comumente diagnosticada na rotina clínica. Esta anomalia ocorre devido ao, principalmente, cruzamento de consanguinidade.

O diagnóstico precoce de ectopia ureteral é fundamental para evitar o desencadeamento de sequelas e o quanto antes for realizado a intervenção cirúrgica, maior a chance de eficácia na resolução do problema.

O tratamento mais efetivo é a laparotomia exploratória, onde é feita a correção dos ureteres ectópicos. O proprietário deve ser conscientizado dos riscos do cruzamento entre consanguinidades e orientado quanto à necessidade da castração do animal, já que é uma anomalia hereditária.

É importante também conscientizar o proprietário quanto à terapêutica da infecção urinária, pois é de difícil controle e, se não administrados corretamente os medicamentos, pode ocorrer resistência dos microrganismos, reduzindo as chances de um tratamento eficiente. Quando tratado corretamente, ocorre redução das complicações pós-operatórias como a incontinência urinária.

\section{REFERÊNCIAS}

BIANCHI, S. P.; GOUVÊA, A. S.; MACEDO, A. S.; VALENTE, F. S.; LEDUR, G. R.; ALIEVI, M. M.; CONTESINI, E. A. Ureter ectópico extramural em cadela. Departamento de medicina animal, Universidade Federal do Rio Grande do Sul (UFRGS), Porto Alegre, Acta Scientiae Veterinariae, p. 1-4, 2013.

BRAGATO, N. Fisiologia renal e insuficiência renal aguda em pequenos animais: causas e consequências. 2013. 50f. Trabalho de conclusão de curso 
(Graduação em Medicina Veterinária) - UFG - Universidade Federal de Goiás, Goiânia, 2013.

CHEW, D.J.; DIBARTOLA, S.P.; SCHENCK, P.A. Distúrbios de micção e Incontinência urinária. In: CHEW, D.J. (Ed). Urologia e Nefrologia do cão e do gato. 2. ed. Rio de Janeiro: Elsevier, 2011, p.409- 433.

COSTA NETO, J. M. da.; SILVA, A. E. da.; MARTINS FILHO, E. F.; RIBEIRO, L. G. R.; GAMA, R. O. E.; PENHA, E. M.; TORÍBIO, J. M. M. L. de.; GOMES JÚNIOR, D. C. Ectopia ureteral em cães: relato de dois casos. Arq. Ciênc. Vet. Zool.UNIPAR, Umuarama, v. 14, n. 2, p. 151-156, jul./dez. 2011.

FOSSUM, T.W. Cirurgia do rim e do ureter. In: FOSSUM T.W. (Ed). Cirurgia de pequenos animais. 3. ed. Rio de Janeiro: Elsevier, 2008. cap. 25, p. 646 - 654.

GRANT, D.; FORRESTER, S.D. Doenças do sistema urogenital. In: BIRCHARD, S. J.; SHERDING, R. G. Clínica de pequenos animais. 3. ed. São Paulo: Roca, 2008, p. 906-907.

GRAUER, G.F. Distúrbios do trato urinário. In: COUTO, C. G.; NELSON, R. W. Medicina Interna de pequenos animais. 4. Ed. Rio de Janeiro: Elsevier, 2010. cap. 41 , p. $609-623$.

MCLOUGHLIN, M.A.; BJORLING, D.E. Ureteres. In: SLATTER, D. (Ed). Manual de cirurgia de pequenos animais. 3. ed. Barueri: Manole, 2007. cap. 110, p.16191623.

OLIVEIRA, D. M. M. C.; REUSING, M. S. O.; SILVA, D. M. Ectopia ureteral bilateral em cadelas: diagnóstico, tratamento cirúrgico e evolução clínica. Departamento de Medicina Veterinária, Setor de Ciências Agrárias, Universidade Federal do Paraná (UFPR), Curitiba, Acta Scientiae Veterinariae, v. 33, n. 41, p. 1 - 4, 2013.

SILVA, M. N.; LARANJEIRA, D. F.; PENHA, E. M.; ORIÁ, A. P.; COSTA NETO, J. M.; BARROUIN - MELO. Ectopia ureteral unilateral congênita em uma cadela Teckel Dachshund com pelagem arlequim - relato de caso. Arq. Bras. Med. Vet. Zootec., v. 64, n. 6 , p. $1504-1510,2012$. 